\title{
The Caenorhabditis elegans APC-related gene apr-1 is required for epithelial cell migration and Hox gene expression
}

\author{
Erika Fröhli Hoier, ${ }^{1}$ William A. Mohler, ${ }^{2}$ Stuart K. Kim, ${ }^{3}$ and Alex Hajnal ${ }^{1,4}$ \\ ${ }^{1}$ Division of Cancer Research, Department of Pathology, University of Zürich, CH-8091 Zürich, Switzerland; ${ }^{2}$ Laboratory \\ of Molecular Biology, University of Wisconsin-Madison, Madison, Wisconsin 53706 USA; ${ }^{3}$ Department of Developmental \\ Biology, Stanford University Medical Center, Stanford California 94305-5329 USA
}

\begin{abstract}
Inactivation of the Caenorhabditis elegans APC-related gene (apr-1) has pointed at two separate functions of apr-1. First, apr-1 is required for the migration of epithelial cells during morphogenesis of the embryo. In this process, APR-1 may act in a Cadherin/ $\alpha$-Catenin/ $\beta$-Catenin complex as a component of adherens junctions. Second, apr-1 is required for Hox gene expression, most likely by positively regulating the activity of the Wingless signaling pathway. During embryogenesis, apr-1 is required for the expression of ceh-13 labial in anterior seam and muscle cells and during larval development, apr-1 is necessary for the expression of lin-39 deformed in the vulval precursor cells. Thus, APR-1 may positively regulate the activity of the $\beta$-Catenin/Armadillo-related proteins HMP-2 in migrating epithelial cells and BAR-1 in the vulval precursor cells.
\end{abstract}

[Key Words: Caenorhabditis elegans; cell migration; vulva; APC; Hox gene; Wingless]

Received November 16, 1999; revised version accepted February 15, 2000.

The human APC tumor suppressor gene is mutated in most cases of inherited colorectal cancer (for review, see Kinzler and Vogelstein 1996; Polakis 1997). Humans carrying a germ-line mutation in one APC allele develop hundreds of colonic polyps at a young age, in which the second, wild-type APC allele has been lost spontaneously. Some of these polyps eventually accumulate additional mutations and progress to carcinomas. Spontaneous mutations in both APC alleles have also been observed in the majority of sporadic colon carcinomas. Biochemical studies have identified a number of APCbinding partners and suggested possible functions for APC. In particular, binding of APC to $\beta$-Catenin (Rubinfeld et al. 1993) is thought to regulate the activity of $\beta$-Catenin in the evolutionary conserved Wingless (Wnt) signal transduction pathway (for review, see Polakis 1997; Wodarz and Nusse 1998; Peifer 1999). In both familial and sporadic forms of colorectal cancer, the vast majority of APC mutations that have been characterized result in carboxy-terminal truncations of the APC protein and eliminate part of the $\beta$-Catenin-binding site (Polakis 1995). Colon cancer cells that express truncated APC often exhibit elevated levels of cytoplasmic $\beta$-Catenin and an increased activity of the Wnt signaling pathway, suggesting that wild-type APC may negatively regulate $\beta$-Catenin function (Munemitsu et al. 1995; Ko-

${ }^{4}$ Corresponding author.

E-MAIL ahajnal@pathol.unizh.ch; FAX (411) 255-4508. rinek et al. 1997; Morin et al. 1997). Supporting this model, mutations in the Drosophila APC homologs dAPC1 and dAPC2 (or E-APC) result in the constitutive activation of the $\beta$-catenin homolog armadillo in different tissues (Ahmed et al. 1998; McCartney et al. 1999; $\mathrm{Yu}$ et al. 1999). However, studies of Xenopus laevis axis induction and early Caenorhabditis elegans embryonic development have suggested an activating rather than an inhibitory function for APC in the Wnt signaling pathway (Rocheleau et al. 1997; Vleminckx et al. 1997). In addition to its role in Wnt signaling, it has been proposed that vertebrate APC may control the migration and adhesion of epithelial cells (Nathke et al. 1996; Wong et al. 1996; Pollack et al. 1997), cell cycle progression (Baeg et al. 1995), and cell death (Morin et al. 1996).

During C. elegans development, activation of the Wnt signaling pathway induces the expression of Hox genes in different cell types (Eisenmann et al. 1998; Jiang and Sternberg 1998; Maloof et al. 1999). The C. elegans Hox genes are organized in an evolutionarily conserved gene cluster consisting of the four genes ceh-13, lin-39, mab5, and egl-5 that are the homologs of the Drosophila Hox genes labial, deformed, antennapedia, and abdominal$B$, respectively (for review, see McGinnis and Krumlauf 1992; Lawrence and Morata 1994; Salser and Kenyon 1994). They are expressed in distinct domains along the anterior-posterior $(\mathrm{A} / \mathrm{P})$ axis and specify cell fates in their expression domains by controlling diverse processes such as cell division, polarity, migration, adhesion, fusion, and death. The $\beta$-catenin/armadillo-related 
gene bar-1 is an essential regulator of the Wnt signaling pathway, leading to the induction of Hox gene expression during postembryonic development (Eisenmann et al. 1998; Maloof et al. 1999). In particular, bar-1 is required for the transduction of a Wnt signal that specifies the vulval equivalence group in the six hypodermal Pn.p cells P3.p through P8.p (P3-8.p). In response to this Wnt signal, P3-8.p express the Hox gene lin-39 and become vulval precursor cells (VPCs). The anterior Pn.p cells (P1.p and P2.p) and posterior Pn.p cells (P9.p-P11.p) that may not receive a Wnt signal do not express lin-39 and adopt a fused $(\mathrm{F})$ cell fate; they dissolve their adherens junctions and fuse with the surrounding hypodermal syncytium hyp7 (Sulston and Horvitz 1977). In animals carrying a loss-of-function mutation in bar-1, P3-8.p frequently fail to express lin-39 and adopt an F fate instead of a VPC fate (Eisenmann et al. 1998).

The hmp-2 gene encodes another C. elegans $\beta$-Catenin homolog that is required for epithelial cell migration and elongation during morphogenesis of the embryo /Costa et al. 1998). HMP-2 does not appear to act in a Wnt signaling pathway, but rather, it functions as a component of the Cadherin $/ \alpha$-Catenin/ $\beta$-Catenin complex at the adherens junctions of epithelial cells in the epidermis (which is called hypodermis in C. elegans).

We have taken a genetic approach to study the role of the C. elegans APC-related gene apr-1 (Rocheleau et al. 1997) during embryogenesis and vulval development. Unlike the truncations found in human (Polakis 1995), mouse (Su et al. 1992), and Drosophila APC (Ahmed et al. 1998), the apr-1 mutation described in this work is predicted to disrupt the synthesis of the entire APR-1 protein. Our analysis of the apr-1 loss-of-function phenotype points at two separate functions of apr-1. First, apr-1 is required for the migration and elongation of hypodermal cells that enclose the embryo during morphogenesis. In this context, APR-1 appears to function as a component of the hypodermal adherens junctions together with HMR-1 Cadherin, HMP-1 $\alpha$-Catenin, and HMP- $2 \beta$-Catenin. Second, apr-1 controls the expression of Hox genes during embryogenesis and vulval development, most likely by positively regulating the activity of the Wnt signaling pathway. In both processes, APR-1 may be necessary for the activity of $\beta$-Catenin/Armadillo-related proteins.

\section{Results}

\section{Isolation of an apr-1 loss-of-function mutation}

A database search of the complete C. elegans genome sequence revealed the presence of a single APC homolog that had been previously named apr-1 (Rocheleau et al. 1997). APR-1 and human APC1 both contain seven Armadillo repeats in their amino-terminal domains that are $31 \%$ identical and a conserved PDZ-binding motif at their carboxyl termini. The putative $\beta$-Catenin/Armadillo-binding site in the central region of APR-1 shows weaker sequence similarity when compared with human APC1.
To isolate a loss-of-function mutation in apr-1, a library consisting of $\sim 5 \times 10^{5}$ mutagenized animals was screened for deletions in the apr-1 genomic region using a nested PCR assay (see Materials and Methods). A single allele, apr-1(zh10), was isolated from this screen and used for the subsequent experiments. apr-1(zh10) animals contain a deletion of $1414 \mathrm{bp}$ that removes the first, second, and most of the third exon (Fig. 1A). The apr1(zh10) deletion is likely to completely eliminate gene function, as it removes the ATG translational initiation codon as well as the part of the $5^{\prime}$ promoter region that contains a likely transcriptional start site with a TATAbox (Bensimhon et al. 1983).

The following observations indicate that loss of apr-1 function causes a zygotic lethal phenotype. The progeny of apr-1(zh10)/+ heterozygous parents contained no viable apr-1(zh10) homozygous animals as determined by PCR analysis $(n=48)$ or by scoring the segregation of a linked unc-29(e1072) mutation (see Materials and Methods). The lethality associated with apr-1(zh10) could be rescued by germ-line transformation with a plasmid containing a 7.3-kb genomic fragment of the apr-1 locus (Fig. 1A). Furthermore, apr-1(zh10) homozygous animals only survived to adulthood if they carried an extrachromosomal array with the rescuing apr-1 transgene.
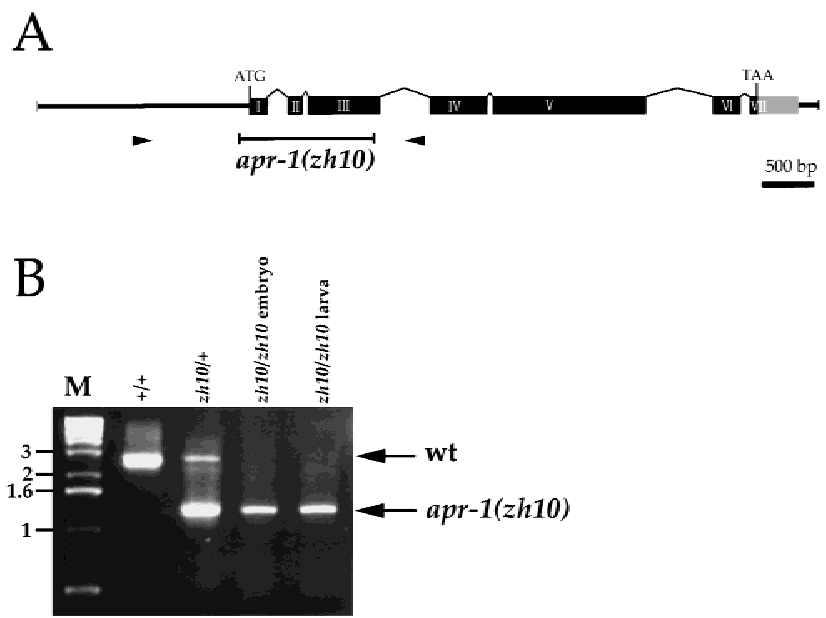

Figure 1. Genomic structure of the apr-1 locus. (A) A 7.3-kb fragment (apr-1wt) containing all the sequences necessary to rescue the apr-1 loss-of-function phenotype is shown. Exons are indicated by thick lines and are numbered. The positions of the ATG initiation and TAA stop codons are shown. Exon-intron boundaries were confirmed by RT-PCR analysis (data not shown). The extent of the 1414-bp deletion in apr-1(zh10) animals is indicated by the line underneath the genomic structure. The arrowheads indicate the position of the primers $\mathrm{O} 95$ and O101 that were used for the PCR analysis shown below. $(B)$ Single-animal PCR analysis of a wild-type larva $(+++)$, a heterozygous apr-1(zh10) unc-29(e1072)/lin-10(e1439) larva (zh10/+), an apr-1(zh10) unc-29(e1072)-arrested embryo (zh10/zh10 embryo) and an apr-1(zh10) unc-29(e1072)-arrested L1 larva (zh10/ zh10 larva). (M) Molecular weight standards; the numbers to the left of this lane indicate the length of relevant markers in kilobase pairs $(\mathrm{kb})$. The arrows at right indicate the $2.9-\mathrm{kb}$ product from the wild-type and the $1.5-\mathrm{kb}$ product from the $z$ h10 allele. 
To determine at what stage of development apr1(zh10) mutants die, we monitored the development of a known number of eggs laid by apr-1(zh10)/+ heterozygous parents. A total of $77 \pm 4 \%$ of the eggs hatched and developed into viable animals of the genotype apr1 (zh10) $/+$ or $+/+, 15 \pm 3 \%$ arrested during embryogenesis and $8 \pm 3 \%$ arrested shortly after hatching during the first larval (L1) stage $(n=450)$. All arrested embryos and L1 larvae were homozygous for apr-1(zh10) as determined by PCR analysis $(n=28$, Fig. $1 B)$. Thus, approximately two-thirds of homozygous apr-1(zh10) mutants arrest during embryogenesis and the remaining third during the L1 stage. To test whether apr-1(zh10) L1 larvae may have escaped from the embryonic lethality because of rescue by maternal apr-1 activity, we examined apr-1(zh10) germ-line mosaic animals (see Material and Methods). However, because loss of apr-1 function in the germ line causes a sterile phenotype, we were unable to examine the contribution of maternal apr-1 activity to embryogenesis.

Loss of apr-1 function causes multiple morphogenesis defects in the embryo

During wild-type morphogenesis, contralateral pairs of hypodermal cells that are born on the dorsal side migrate ventrally along the left and right sides of the embryo until they reach the ventral midline and the hypodermis fully encloses the embryo, a process called ventral closure (Priess and Hirsh 1986; Williams Masson et al. 1997; Costa et al. 1998). At the same time, dorsal hypodermal cells intercalate and then fuse to each other, thereby forming the dorsal syncytium (Podbilewicz and White 1994; Williams Masson et al. 1998). After the cell migrations and fusions are completed, the hypodermis is organized in two rows of ventral and lateral epithelial cells on each side of the embryo plus a dorsal syncytium. Finally, the cells begin to elongate along the $\mathrm{A} / \mathrm{P}$ axis until the length of the body has increased about fourfold.

apr-1(zh10) embryos that arrested before undergoing elongation ruptured on the ventral side, suggesting that apr-1 may be required for ventral closure (Fig. 2A,B). To study the function of apr-1 in hypodermal cells, apr1(zh10) embryos were fixed at various stages and stained with the mAb MH27 that recognizes the adherens junction marker JAM-1 (Fig. 2C,D; Francis and Waterston 1985; M. Köppen and J.D. Hardin, pers. comm.). Alternatively, embryos carrying a jam-1::GFP reporter on the chromosomally integrated array jcIs1 were observed by four-dimensional time-lapse microscopy (Fig. 3; Mohler et al. 1998). Four kinds of defects could be observed in apr-1(zh10) embryos.

First, the migration of hypodermal cells was disrupted. Of 22 apr-1(zh10) embryos observed by four-dimensional microscopy, 18 arrested before undergoing elongation. In 13 of these 18 embryos, hypodermal cells initiated ventral migration, but they did not reach the ventral midline and failed to enclose the embryo (Fig. 3A,B). In the other five arrested embryos, the two pairs of anterior leading cells did reach the ventral midline and ventral closure
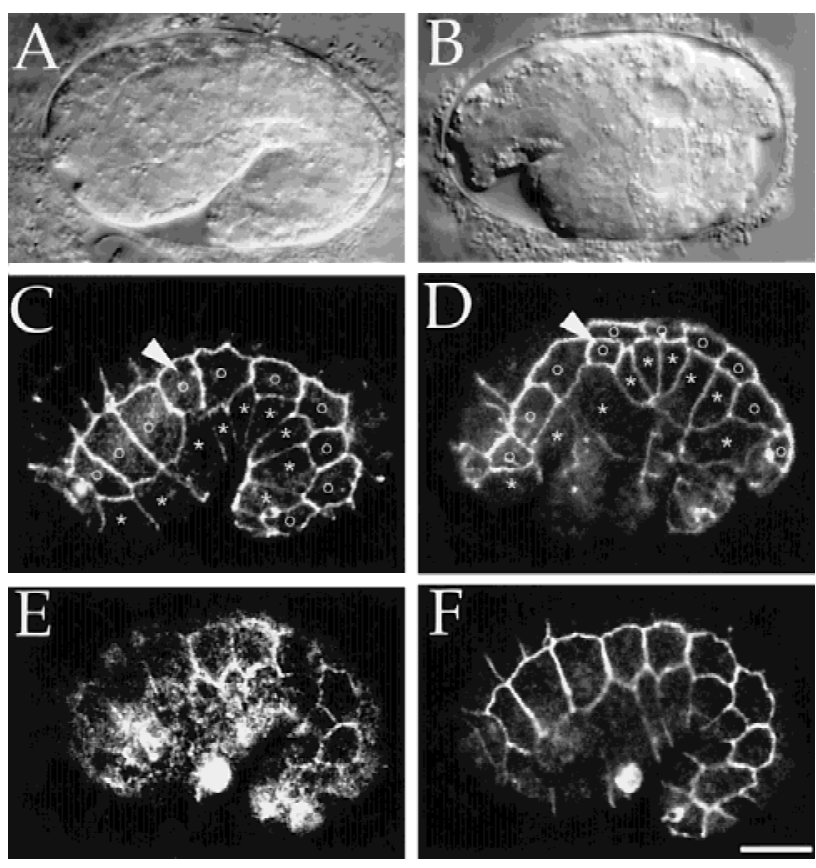

Figure 2. Embryonic phenotypes caused by the apr-1(zh10) deletion and APR-1 expression pattern in hypodermal cells. Nomarski photomicrographs of a wild-type embryo at the 1.5-fold stage $(A)$ and a terminal stage apr-1(zh10) embryo that had ruptured ventrally and failed to elongate $(B)$. Morphology of hypodermal cells stained with the mAb MH27 in a wild-type 1.5-fold embryo $(C)$ and a terminal stage apr-1(zh10) embryo $(D)$. The circles in $C$ and $D$ denote the lateral seam cells, the asterisks indicate the ventral hypodermal cells, and the arrowheads point at the position of the V1 seam cell. Note the rupture at the ventral midline, the dorsal retraction of ventral hypodermal cells, and the mislocalization of V1 (arrowhead) in the apr1(zh10) embryo shown in D. Partial localization of APR-1 at the adherens junctions in a zhEx2[apr-1wt] embryo stained with APR-1 antibodies $(E)$ and $\mathrm{mAb}$ MH27 $(F)$. All embryos are shown from a lateral view; anterior is left and dorsal is up. The apr1(zh10) embryos were the descendants of apr-1(zh10) unc29(e1072)/lin-10(e1439) mothers. Scale bar in F, $10 \mu \mathrm{m}$.

was initiated, but the embryos ruptured on the anterior or posterior ventral side at about the 1.25 -fold stage. In all 18 terminal stage apr-1(zh10) embryos, the hypodermis had retracted dorsally and inner cells from the gut and other tissue protruded (Fig. 2D). The remaining four apr-1(zh10) embryos that enclosed and elongated may have hatched and arrested as L1 larvae as described above.

Second, in 7 of 10 apr-1(zh10) embryos, the dorsal pairs of hypodermal cells failed to intercalate (Fig. 3C,D; for the remaining 8 embryos, dorsal intercalation could not be scored because they were observed from a ventral view.). Although some cell fusions between the misaligned hypodermal cells occurred (arrowheads in Fig. $3 \mathrm{C}, \mathrm{D})$, no dorsal syncytium was formed in these seven embryos. All embryos exhibiting dorsal intercalation defects also failed to undergo ventral closure.

Third, hypodermal cells did not elongate along the $\mathrm{A} / \mathrm{P}$ axis. At a time point when wild-type embryos had 


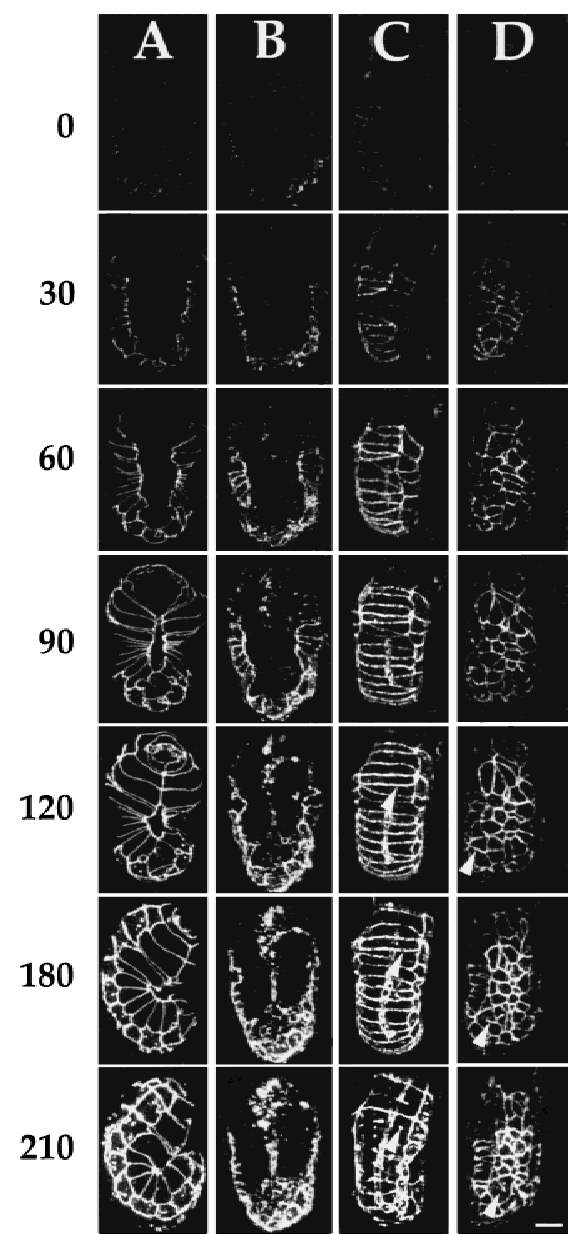

Figure 3. Ventral closure and dorsal intercalation defects in apr-1(zh10) embryos observed by four-dimensional microscopy. The migration of hypodermal cells in embryos carrying the adherens junction marker jcIs1[jam-1::GFP] was observed by twophoton excitation microscopy and four-dimensional reconstructions were done as described (Mohler and White 1998; Mohler et al. 1998). Ventral views of a developing wild-type $(A)$ and an apr-1(zh10) embryo $(B)$; dorsal views of a developing wild-type $(C)$ and another apr-1(zh10) embryo $(D)$. The time point when JAM-1::GFP could first be detected was taken as reference point 0 and is shown in the top frames of $A-D$. The numbers at left of the following frames indicate the time points relative to the reference point in minutes. Note in $B$ the failure of the ventral hypodermal cells to reach the ventral midline and in $D$ the lack of intercalation between the dorsal hypodermal cells. The arrowheads in $C$ and $D$ indicate fusing cells. The embryos were descendants of apr-1(zh10) unc-29(e1072)/lin-10(e1439); jcIs1[jam-1::GFP] mothers. In all embryos, anterior is up. Scale bar in $D, 10 \mu \mathrm{m}$.

elongated about two- to threefold, hypodermal cells in arrested apr-1(zh10) embryos had retained their square shape and the length of the embryos had not increased $>1.25$-fold (Fig. 3; data not shown).

Fourth, the lateral anterior hypodermis was frequently disorganized in apr-1(zh10) mutants. In wild-type embryos, 10 hypodermal cells ( $\mathrm{H} 0, \mathrm{H} 1, \mathrm{H} 2, \mathrm{~V} 1-\mathrm{V} 6$, and $\mathrm{T})$ form the lateral row of seam cells on each side of the embryo (Fig. 2C; Sulston et al. 1983). In $81 \%$ of apr1(zh10) embryos, the two anterior seam cells $\mathrm{H} 2$ and V1 were mislocalized $(n=47)$. V1 was often shifted dorsally or ventrally (arrowhead in Fig. 2D) and H2 moved posterior to make direct contact with V2.

Similar ventral closure and elongation defects have been observed in hmr-1 mutant embryos and in hmp-1 or hmp-2 mutants that lack zygotic and maternal gene activity (Costa et al. 1998). On the other hand, hmr-1, hmp1, or hmp-2 mutants do not exhibit dorsal intercalation defects or the misalignment of the anterior seam cells $\mathrm{H} 2$ and V1 that was observed in apr-1(zh10) mutants (Costa et al. 1998; our observation), suggesting that apr-1 may perform additional functions in the dorsal hypodermis and in anterior seam cells that do not require hmr-1, $h m p-1$, or hmp-2 activity. hmr-1, hmp-1, and hmp-2 encode proteins that are similar to vertebrate Cadherins, $\alpha$-Catenin, and $\beta$-Catenin, respectively, and are localized at hypodermal adherens junctions. We therefore asked whether APR-1 may also be a component of the hypodermal adherens junctions. Because the abundance of APR-1 was too low to allow the detection of endogenous APR-1 in immunohistochemistry experiments, multiple copies of wild-type apr-1 were introduced on an extrachromosomal array (zhEx2) to increase APR-1 expression levels. In $z h E x 2$ embryos, APR-1 was partially localized at adherens junctions, but some cytoplasmic staining could be detected as well (Fig. 2E,F). No staining could be observed with APR-1 preimmuneserum and the addition of an excess of soluble APR-1 antigen completely blocked the staining shown in Figure 2E.

In summary, apr-1 is necessary for at least four different processes during morphogenesis of the embryo, for the ventral migration, dorsal intercalation, and elongation of hypodermal cells and for the alignment of the anterior seam cells $\mathrm{H} 2$ and $\mathrm{V} 1$.

apr-1 is required for expression of the Hox gene ceh-13 during embryogenesis

A mutation in the Hox gene ceh-13 causes a similar mislocalization of the anterior seam cells H2 and V1 (Brunschwig et al. 1999). ceh-13 specifies cell fates in the anterior domain of the embryo, but it is not required for ventral closure, dorsal intercalation, or elongation of the embryo. Thus, one possible explanation for the mislocalization of the anterior seam cells $\mathrm{H} 2$ and V1 in apr1(zh10) embryos is that apr-1 may control the expression of the Hox gene ceh-13.

To test this hypothesis, we examined the expression pattern of CEH-13 in apr-1(zh10) embryos. We used a CEH-13::GFP reporter transgene on the chromosomally integrated array swIs1 to observe CEH-13 expression (Wittmann et al. 1997). swIs1[ceh-13::GFP] embryos at the 1.25-fold stage showed strong GFP expression in the seam cells $\mathrm{H} 2$ and V1, in anterior muscle cells, and in ventral nerve cord (VNC) precursors in the central body region (Fig. 4A-C), similar to the expression pattern observed in embryos stained with CEH-13 antibodies (Brunschwig et al. 1999). In 82\% of apr-1(zh10); 
Figure 4. apr-1 controls ceh-13 expression in anterior cells of the embryo. CEH13::GFP expression in lateral $(A)$ and middle (B) confocal sections through a wild-type 1.25-fold embryo and a Nomarski image of the same embryo $(C)$. Lateral $(D)$ and middle $(E)$ confocal sections through an apr1(zh10) embryo arrested before elongation and a Nomarski image of the same embryo $(F)$. The arrows in $A$ indicate the nuclei of $\mathrm{H} 2$ and V1. The arrowheads in $B, D$, and $E$ point at the VNC precursors and in $F$ at the site of ventral rupture. Note the absence of CEH-13::GFP expression in the lateral sections of the apr-1(zh10) embryo shown in $D$. Both embryos are shown from a lateral view; anterior is left and dorsal is up. The
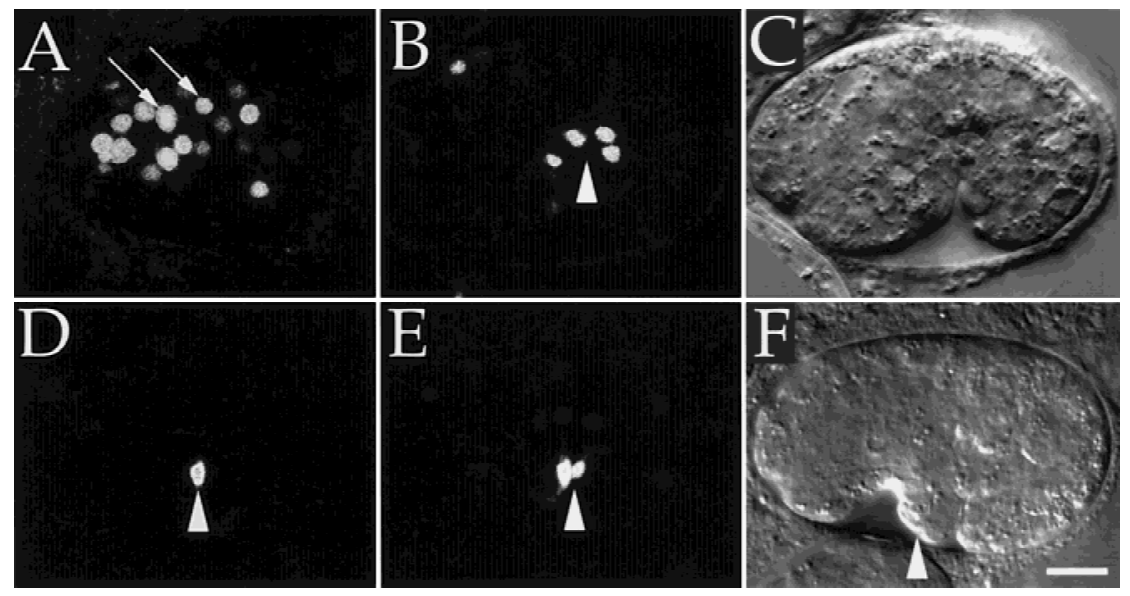
full genotype of the embryo shown in $A-C$

was him-5(e1490); swIs1 [ceh-13::GFP]; the apr-1(zh10) embryo shown in D-F was a descendant of an apr-1(zh10) unc-29(e1072)/unc13(e51) lin-11(n566); him-5(e1490); swIs1[ceh-13::GFP] mother. Scale bar in F, $10 \mu \mathrm{m}$.

swIs1[ceh-13::GFP] embryos, GFP expression was absent in anterior muscle and seam cells, whereas the VNC precursors continued to express CEH-13::GFP in all cases examined $(n=39$, Fig. $4 \mathrm{D}-\mathrm{F})$. The loss of $\mathrm{CEH}-13$ expression in the anterior seam cells $\mathrm{H} 2$ and $\mathrm{V} 1$ is unlikely to be due to the absence of these cells, because the expression pattern of the adherens junction marker JAM-1 indicated that $\mathrm{H} 2$ and V1 were always present in the anterior domain of apr-1(zh10) embryos (Fig. 2D). Thus, apr-1 is necessary for expression of the Hox gene ceh-13 in anterior cells but not in the VNC precursors that are located in the central body region.

\section{APR-1 is expressed in the vulval precursor cells}

During the early L1 stage, 6 pairs of hypodermal cells migrate along the right and left sides of the larva to the ventral midline, where they interdigitate and align in a row of 12 Pn cells along the $\mathrm{A} / \mathrm{P}$ axis $(\mathrm{P} 1$ designates the anterior-most and P12 the posterior-most cell). Shortly after reaching the ventral midline, each Pn cell divides into a Pn.a neuroblast and a hypodermal Pn.p cell (Sulston and Horvitz 1977). Finally, a Wnt signal specifies the VPC fate in P3-8.p (Eisenmann et al. 1998).

The larval expression pattern of APR-1 was studied by staining animals carrying the $z h E x 2[a p r-1 w t]$ array with APR-1 antibodies or by observing GFP expression in a strain carrying an APR-1::GFP reporter transgene on the integrated array zhIs2. The adherens junctions were visualized by staining with the mAb MH27. In early L1 larvae, APR-1 was expressed in the 12 Pn cells as they were descending toward the ventral midline (Fig. 5A,B). In L3 stage hermaphrodites, APR-1 was strongly expressed in P3-8.p, but no APR-1 could be detected in anterior (P1.p and P2.p) or posterior (P9.p-P12.p) Pn.p cells (Fig. 5C,D; data not shown). In addition, APR-1 was expressed in the seam cells (arrowheads in Fig. 5C,D), in the excretory cell and in the excretory canal cell during the L1 stage (horizontal arrow in Fig. 5A,B), and in some unidentified neurons in the head region (not shown).
Similar to the staining observed in embryos, some APR1 staining was localized at the adherens junctions, whereas another fraction of APR-1 could be detected in the cytoplasm (Fig. 5C-F). The specific expression of APR-1 in the VPCs raised the possibility that apr-1 may act during vulval development.

\section{apr-1 is necessary for the specification of the vulval} equivalence group

We devised two different approaches to inactivate apr-1 function in the Pn.p cells without affecting apr-1 activity during embryogenesis. First, we used cre/loxP-mediated recombination to inactivate a rescuing apr-1 transgene (Kilby et al. 1993). To this end, loxP sites were introduced into the rescuing apr-1 construct such that cremediated recombination would result in the excision of all but the first exon of apr-1 (loxP $>a p r-1>\operatorname{lox} P$; Fig. 6A). cre recombinase was expressed under control of the Pn.p cell-specific lin-31 promoter (1in-31::cre; Tan et al. 1998). The $\operatorname{lox} P>$ apr-1 $>\operatorname{lox} P$ and lin-31::cre plasmids were introduced into apr-1(zh10) animals on two separate extrachromosomal arrays, yielding a strain of the genotype apr-1(zh10); zhEx11[loxP > apr-1 > loxP]; zhEx12[lin-31::cre] (see Materials and Methods). In single animals from this strain, the expected recombination product could be detected by PCR analysis (Fig. 6A). As a second approach, we performed tissue-specific RNA-mediated interference (RNAi; Fire et al. 1991). For this purpose, a plasmid carrying anti-sense apr-1 cDNA under control of the Pn.p cell-specific lin-31 promoter (1in-31::apr-1i; Fig. 6B) was introduced into wild-type animals on the integrated array gaIs44. No APR-1 protein was detectable in the VPCs of gaIs44; zhEx2lapr$1 w t]$ animals, whereas the seam cells in the same animals continued to express APR-1 as determined by antibody staining (data not shown).

Both approaches yielded animals displaying essentially the same vulval phenotype, although with a different penetrance. In 15\% of apr-1(zh10); zhEx11[loxP > apr- 

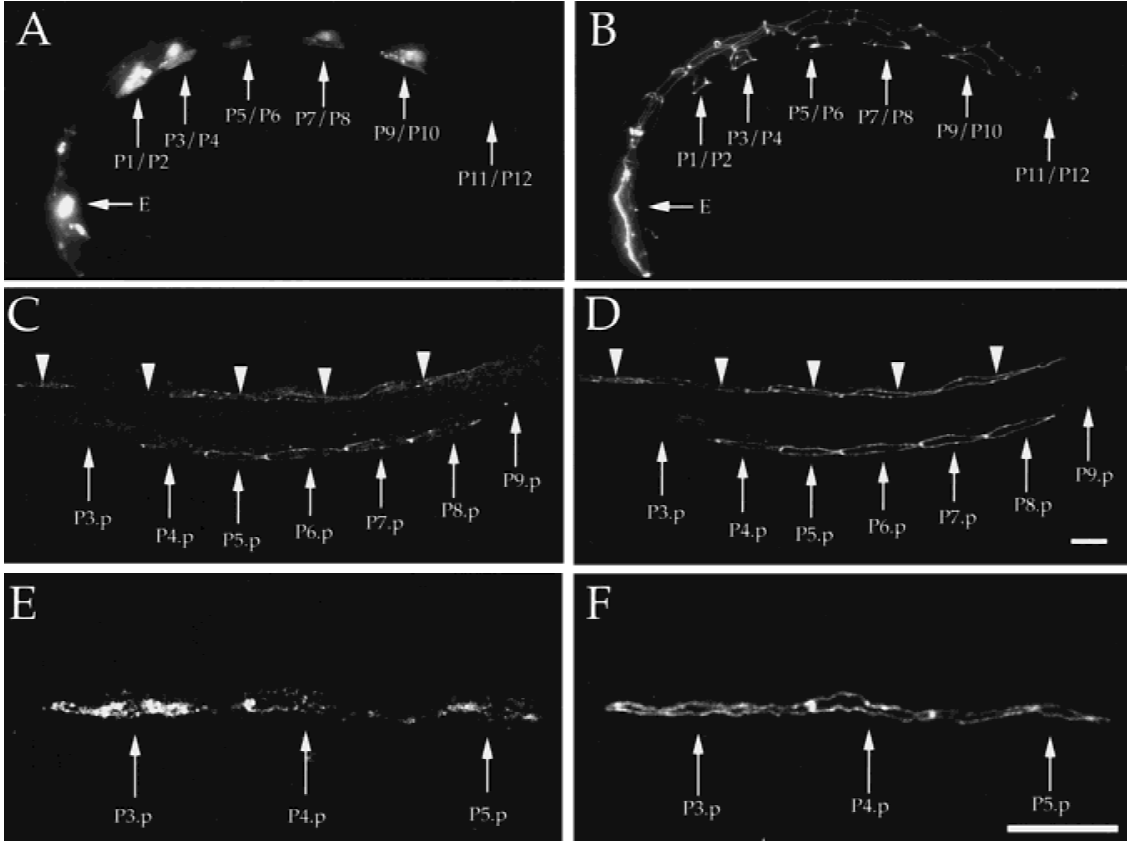

Figure 5. APR-1 expression pattern during larval development. (A) APR-1::GFP expression and $(B) \mathrm{mAb} \mathrm{MH} 27$ staining of an L1 larva carrying the zhIs2[apr-1::GFP] array. The vertical arrows in $A$ and $B$ point at the six pairs of $\mathrm{P}$ cells that were descending from the left and right sides toward the ventral midline, the horizontal arrow points at the excretory cell body. $(C)$ APR-1 antibody and $(D)$ mAb MH27 staining of an L3 larva carrying the zhEx2[apr$1 w t]$ array. Note the APR-1 expression in the VPCs (P4-8.p) indicated by the vertical arrows and in the seam cells indicated by the arrowheads. In this animal, P3.p had adopted an $\mathrm{F}$ fate (as observed in $39 \%$ of wild-type animals) and did not express APR-1. No APR-1 expression was detectable in the anterior (P1-2.p) or posterior (P9-11.p) Pn.p cells (P1.p, P10.p, and P11.p are not shown). (E) Higher magnification of APR-1 antibody, and $(F)$ mAb MH27 staining of P3-5.p in an animal in which P3.p had adopted a VPC fate. All larvae are shown from a lateral view, anterior is left. Scale bars in $D$ and $F, 10 \mu \mathrm{m}$.
1 > loxP]; zhEx12[lin-31::cre] and in $86 \%$ of gaIs44[lin31::apr-1i] animals, P3-8.p adopted an F cell fate instead of induced $\left(1^{\circ}\right.$ or $\left.2^{\circ}\right)$ or uninduced $\left(3^{\circ}\right)$ VPC fates (Sternberg and Horvitz 1986) as determined by staining of the adherens junctions with the mAb MH27 (Fig. 6C-E; Table 1) or by directly observing the pattern of cell divisions (Table 2, rows 2-6). Fusion of P3-8.p could be detected early in the L2 stage as opposed to the later fusion of P3.p that occurred in $39 \%$ of wild-type larvae at the beginning of the L3 stage (Table 1, row 1; Sternberg and Horvitz 1986; Eisenmann et al. 1998). Direct observation of the cell lineage of P3-8.p in gaIs44[1in-31::apr-1i] animals confirmed that cells that presumably adopted an $\mathrm{F}$ fate did not divide and remained at their original position in the ventral midline throughout vulval development (Table 2). With both approaches, Pn.p cells that were distal to the anchor cell (P3.p and P4.p) were more likely to adopt an $\mathrm{F}$ fate than those proximal to the anchor cell (P6.p, followed by P5.p, P7.p, and P8.p; Tables 1 and 2). From these experiments, we have concluded that apr-1 acts in the Pn.p cells to specify the VPC fate in P3-8.p.

Beside apr-1, the Hox gene lin-39 deformed and the $\beta$-catenin/armadillo-related gene bar-1 are required for specification of the vulval equivalence group (Clark et al. 1993; Wang et al. 1993; Eisenmann et al. 1998). Because a null mutation in bar-1 causes an incompletely penetrant phenotype, we asked whether inactivation of apr-1 in bar-1(0) animals might increase the frequency of the $\mathrm{F}$ fate in P3-8.p. In gaIs44[1in-31::apr-1i]; bar-1(0) double mutants (Table 1, row 6), P3-8.p more frequently adopted an $\mathrm{F}$ fate than in either bar-1(0) or gaIs44[Iin31::apr-1i] single mutants (Table 1, rows 4,5), suggesting that in the absence of bar-1 function, apr-1 may still be necessary for the specification of the VPC fate. apr-1 is required for the expression of the Hox gene lin-39 in P3-8.p

Because bar-1 regulates lin-39 expression in response to a Wnt signal (Eisenmann et al. 1998), we tested whether apr-1 may also be required to induce lin-39 expression in P3-8.p. The expression pattern of LIN-39 was determined by staining L2 and L3 larvae with LIN-39 antibodies (Maloof and Kenyon 1998). In wild-type animals, P3-8.p expressed LIN-39, except for those L3 larvae in which P3.p had adopted an F fate (Fig. 7A,C,E). In all 5 apr-1(zh10); zhEx11[loxP > apr-1 > loxP]; zhEx12[lin31::cre] and all 50 gaIs44[1in-31::apr-1i] animals, no LIN39 expression was detectable in Pn.p cells that had adopted an F fate. An example is shown in Fig. 7, B and D. Consistent with the increasing frequency of the F fate in Pn.p cells distal to the anchor cell, LIN-39 was undetectable in P3.p but strongly expressed in P6.p in most gaIs44[1in-31::apr-1i] animals (Fig. 7F). Furthermore, the down-regulation of LIN-39 expression could be observed in late L1 larvae before Pn.p cells adopted an F fate (10$12 \mathrm{hr}$ posthatching, data not shown), indicating that the loss of LIN-39 expression is a cause and not a consequence of the F fate. In summary, these data have suggested that apr-1 may act in a Wnt signaling pathway that induces LIN-39 expression in P3-8.p.

\section{Discussion}

Our genetic analysis of the APC-related gene apr-1 has revealed distinct functions of apr-1: First, apr-1 is required for the ventral migration, dorsal intercalation, and elongation of hypodermal cells during morphogenesis of the embryo (Fig. 8A). Second, apr-1 regulates Hox 

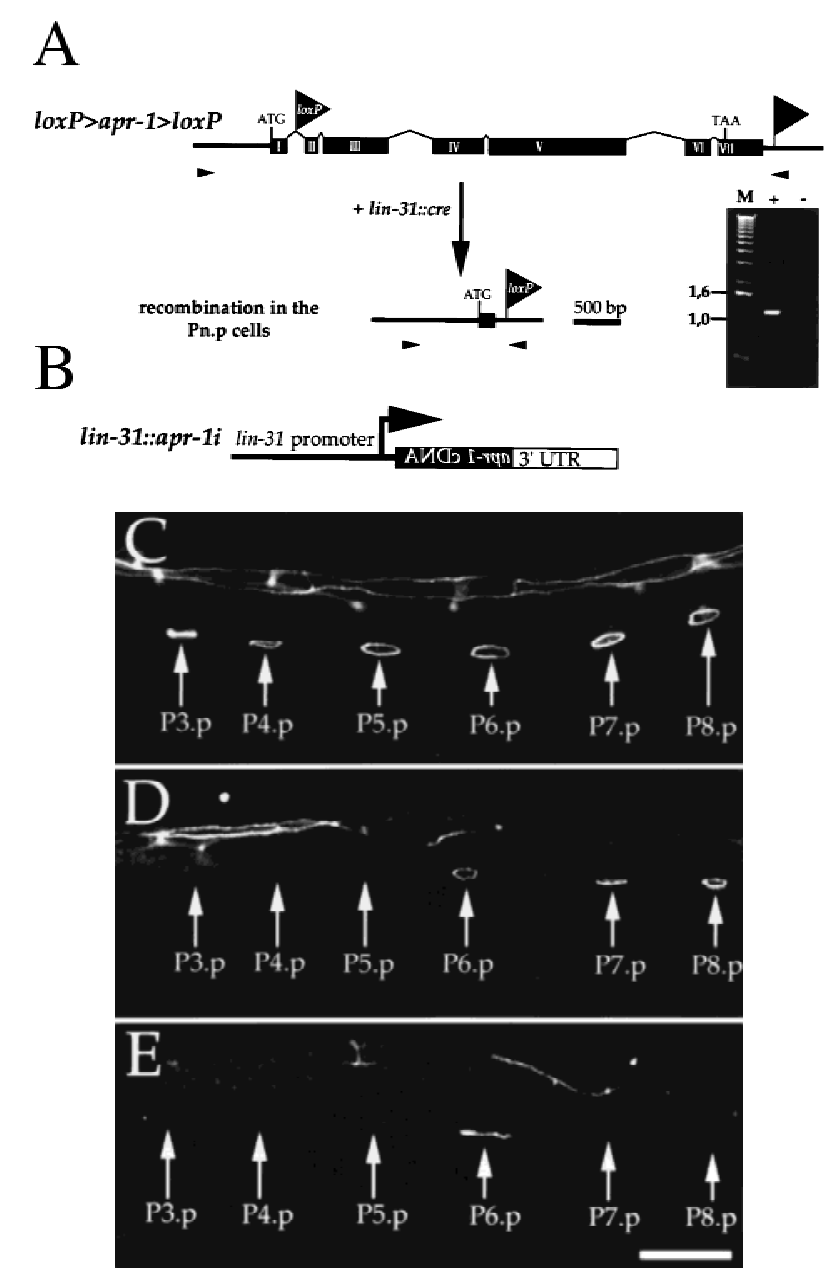

Figure 6. Inactivation of apr-1 in the Pn.p cells causes P3-8.p to adopt an $\mathrm{F}$ fate. $(A)$ Structure of the lox $P>$ apr-1 $>\operatorname{lox} P$ transgene used for cre/loxp-mediated inactivation of apr-1 and of the predicted recombination product. The circular excision product is not shown. The arrowhead below the lox $P>$ apr$1>\operatorname{lox} P$ construct indicates the position of the primers $\mathrm{O} 101$ (see Materials and Methods) and M13reverse (Invitrogen) that were used for the PCR analysis shown at right. (+) The 1.3-kb recombination product obtained by PCR analysis of an L4 larva of the genotype apr-1(zh10); zhEx11[loxP > apr-1 > loxP]; zhEx12[lin-31::cre]; (-) an animal of the genotype apr-1(zh10); zhEx11[loxP $>$ apr-1 $>\operatorname{lox} P]$ analyzed as negative control. The PCR conditions used did not allow amplification of the $6.5-\mathrm{kb}$ product from $\operatorname{lox} P>$ apr-1 $>\operatorname{lox} P$ transgenes that had not undergone cre-mediated recombination. (M) Molecular mass standards; the numbers at left indicate the length of relevant markers in kilobase pairs. (B) Structure of the lin-31::apr-1i construct used for Pn.p cell-specific RNAi. mAb MH27 staining of the VPCs in wild-type $(C)$, apr-1(zh10); zhEx11[loxP > apr-1 > loxP]; zhEx12[lin-31::cre] (D), and gaIs44[lin-31::apr-1i] L2 larvae (E). The arrows point at the positions of the Pn.p nuclei as determined by parallel staining with DAPI (not shown). Note that in the animal shown in D P3.p, P4.p, and P5.p and in the animal shown in E, all Pn.p cells except for P6.p have adopted an F fate, because they failed to stain with the mAb MH27. See Table 1 for more examples and for the complete genotypes of the animals shown. Scale bar in $E, 10 \mu \mathrm{m}$. gene expression. During embryogenesis, apr-1 is required for the expression of the Hox gene ceh-13 labial in anterior cells (Fig. 8A) and during vulval development, apr-1 is necessary for the expression of the Hox gene lin-39 deformed in P3-8.p (Fig. 8B).

\section{apr-1 is required for morphogenesis of the embryo}

apr-1 plays multiple roles during morphogenesis of the embryo. The incomplete penetrance of the different phenotypes is probably due to a variable rescue by maternally expressed apr-1. However, because loss of apr-1 function in the germ line causes complete sterility, we were unable to examine the contribution of maternal apr-1 activity to morphogenesis.

The ventral closure defect is caused by a disruption of hypodermal cell migration. In apr-1(zh10) embryos, hypodermal cells initiate ventral migration, but they stop before reaching the ventral midline. Moreover, in apr1(zh10) larvae that arrest during the L1 stage the hypodermal Pn cells do not descend to the ventral midline, suggesting that apr-1 may also be required for the ventral migration of the Pn cells (data not shown). What may be the role of apr-1 in hypodermal cell migration? One possible model predicts that APR-1 may act in a Cadherin/ $\alpha$-Catenin/ $\beta$-Catenin complex at the adherens junctions. It has been proposed that filopodial contacts must be made between the contralateral pairs of migrating cells before adherens junctions can be formed across the ventral midline and the cells are fixed in their new position (Costa et al. 1998; Raich et al. 1999). In particular, the two pairs of leading cells project actin-rich filopodia toward the ventral midline (Williams Masson et al. 1997). APR-1 may be required together with HMR-1 Cadherin, HMP-1 $\alpha$-Catenin, and HMP- $2 \beta$-Catenin to stabilize the transient filopodial contacts between the pairs of leading cells by attaching actin filaments to the newly forming junctions.

Dorsal intercalation does not depend on hmr-1, hmp-1, or hmp-2 activity, possibly because this process does not involve the formation of new adherens junctions. apr-1, on the other hand, may be required for the directed movement of dorsal hypodermal cells through a microtubule-dependent mechanism that has been proposed for vertebrate APC (Nathke et al. 1996; Pollack et al. 1997). In migrating vertebrate cells, APC was found in clusters near the ends of microtubules that extended into regions of actively migrating plasma membranes and at the sites where two cells first touched. This specific subcellular localization has suggested that APC may recruit microtubules into the extending membrane structures and thus stabilize the direction of cell migration. Although we have not observed a specific localization of APR-1 at the sites of actively migrating membranes, our data are consistent with an analogous role for apr-1 in directing cell movements during ventral closure and dorsal intercalation.

An alternative model explaining both the ventral closure and dorsal intercalation defects predicts that apr-1 may be required for the specification of hypodermal cell 
Table 1. Pn.p cells lacking apr-1 activity frequently adopt an F fate

\begin{tabular}{|c|c|c|c|c|c|c|c|c|c|}
\hline \multirow[b]{2}{*}{ Row } & \multirow[b]{2}{*}{ Genotype } & \multicolumn{6}{|c|}{ Percent fused ${ }^{a}$} & \multirow{2}{*}{$\begin{array}{l}\text { Percent } \\
\text { mutant }{ }^{\mathrm{b}}\end{array}$} & \multirow[b]{2}{*}{ No. ${ }^{c}$} \\
\hline & & P3.p & P4.p & P5.p & P6.p & P7.p & P8.p & & \\
\hline 1 & wild type & 39 & 0 & 0 & 0 & 0 & 0 & 0 & $61^{\mathrm{d}}$ \\
\hline 2 & apr-1; zhEx11[loxP>apr-1>loxP $]^{\mathrm{e}}$ & 33 & $1.4^{\mathrm{f}}$ & 0 & 0 & $0.7^{\mathrm{f}}$ & 0 & 1.4 & 140 \\
\hline 3 & apr-1; zhEx11[loxP>apr-1>loxP];zhEx12[lin-31::cre $]^{\mathrm{g}}$ & 45 & 9 & 4 & 3 & 4 & 4 & 15 & 219 \\
\hline 4 & gaIs44[lin-31::apr-li] & 72 & 60 & 44 & 17 & 35 & 35 & 86 & 57 \\
\hline 5 & bar-1 $(0)^{\mathrm{h}}$ & 66 & 56 & 11 & 2 & 2 & 6 & 62 & 55 \\
\hline 6 & bar-1(0); gaIs 44[1in-31::apr-1i ${ }^{\mathrm{h}}$ & 95 & 88 & 81 & 61 & 54 & 63 & 99 & 103 \\
\hline
\end{tabular}

For each strain, L3 larvae were stained with mAb MH27 to detect the adherens junctions of unfused cells.

${ }^{a}$ Each column indicates the percent frequency at which Pn.p cells adopted an F fate instead of a VPC fate.

${ }^{\mathrm{b}}$ The frequency at which animals with fewer than six VPCs were observed in each strain; animals in which P3.p had adopted an F fate were counted as wild-type.

${ }^{\mathrm{c}}$ The number of animals scored for each strain.

${ }^{\mathrm{d} S i m i l a r}$ data for wild-type (N2) have been reported previously (Eisenmann et al. 1998).

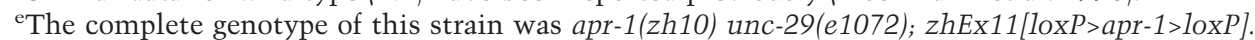

fIn two animals of this strain, P4.p and/or P7.p had adopted an F fate. This could be due to a spontaneous loss of the zhEx11 array in single Pn.p cells or to an incomplete rescue by the apr-1 transgene. In other strains carrying a rescuing apr-1 transgene, individual Pn.p cells adopted an $\mathrm{F}$ fate in $0.4 \%-0.8 \%$ of the animals (data not shown).

${ }^{\mathrm{g}}$ The complete genotype of this strain was apr-1 (zh10) unc-29(e1072); unc-119(e2498); zhEx11[loxP>apr-1>loxP]; zhEx12[lin-31::cre, unc-119(+)].

${ }^{\mathrm{h}}$ The bar-1(ga80) null mutation was used in these experiments (Eisenmann et al. 1998).

fates. In particular, apr-1 may be necessary for the transduction of a Wnt signal that specifies hypodermal cell fates in the embryo (see below). The disruption of cell migration and intercalation could therefore be the consequence of cell fate transformations. This scenario seems most likely in the case of dorsal intercalation because the dorsal hypodermal cells in apr-1 mutants appear to be disorganized even before intercalation normally begins.

The regulation of cell migration by APC is of particular importance in the human intestine, because defects in epithelial cell migration may result in the formation of intestinal polyps (Kinzler and Vogelstein 1996). At the base of the crypts in intestinal epithelia, stem cells continuously proliferate to generate enterocytes that migrate out of the crypts up to the adjacent villi, where they undergo apoptosis. Mutations in APC may lead to the formation of intestinal polyps because they prevent the migration of enterocytes from the proliferative zone at the base of the crypts to the apoptotic zone in the villi, leading to the accumulation of enterocytes in the crypts (Nathke et al. 1996).

In addition to the ventral migration and dorsal intercalation defects, hypodermal cells fail to elongate in apr-1 mutants. Elongation may only be possible after ventral closure and dorsal intercalation have been completed. Alternatively, APR-1 may be required together with HMR-1, HMP-1, and HMP-2 to attach actin filaments to the adherens junctions of the hypodermis. The contraction of these actin filaments along the dorsoventral axis generates the force elongating hypodermal cells along the $\mathrm{A} / \mathrm{P}$ axis, thus driving elongation of the entire embryo (Priess and Hirsh 1986).

apr-1 is required for the expression of the Hox genes ceh-13 and lin-39

Loss of apr-1 function during embryogenesis causes defects in the organization of the anterior seam cells, similar to a mutation in the Hox gene ceh-13 (Brunschwig et

Table 2. Vulval Lineages of Wild-type, gaIs44[lin-31::apr-li], and lin-39(0) animals

\begin{tabular}{|c|c|c|c|c|c|c|c|c|}
\hline Row & Genotype & P3.p & P4.p & P5.p & P6.p & P7.p & P8.p & Phenotype \\
\hline 1 & wild type & S S or F & S S & LLTN & TTTT & NTLL & S S & non-Vul \\
\hline 2 & gaIs44[lin-31::apr-li] & $\mathrm{F}$ & $\mathrm{F}$ & LLTN & TTTT & $\mathrm{F}$ & $\mathrm{F}$ & $\mathrm{Vul}^{\mathrm{a}}$ \\
\hline 3 & gaIs44[lin-31::apr-li] & $\mathrm{F}$ & $\mathrm{F}$ & LLTN & OOOO & $\mathrm{F}$ & SOO & Vul \\
\hline 4 & gaIs44[lin-31::apr-li] & $\mathrm{F}$ & $\mathrm{F}$ & $\mathrm{F}$ & TTTT & $\mathrm{F}$ & $\mathrm{F}$ & Vul \\
\hline 5 & gaIs44[lin-31::apr-li] & $\mathrm{F}$ & $\mathrm{F}$ & $\mathrm{F}$ & 0000 & $\mathrm{~F}$ & $\mathrm{~F}$ & Vul \\
\hline 6 & gaIs44[lin-31::apr-li] & $\mathrm{F}$ & $\mathrm{F}$ & $\mathrm{F}$ & $\mathrm{F}$ & $\mathrm{F}$ & $\mathrm{F}$ & Vul \\
\hline 7 & $\operatorname{lin}-39(0)$ & $\mathrm{F}$ & $\mathrm{F}$ & $\mathrm{F}$ & $\mathrm{F}$ & $\mathrm{F}$ & $\mathrm{F}$ & $\mathrm{Vul}^{\mathrm{b}}$ \\
\hline
\end{tabular}

The cleavage planes of the third round of cell divisions are indicated as follows: $(\mathrm{T})$ Transverse division; $(\mathrm{O})$ oblique division; $(\mathrm{L})$ longitudinal division; (N) cell that did not divide during the third round of division; (S) cell that fused with hyp7 after the first round of cell division; (F) cell that never divided. The shaded area indicates cells that adopted induced $\left(1^{\circ}, 1^{\circ}\right.$-like, or $\left.2^{\circ}\right)$ cell fates. ${ }^{a}$ When inspected under a dissecting microscope, $80 \%$ of gaIs44[1in-31::apr-li] animals displayed a Vul phenotype ( $\left.n>200\right)$.

bData from Clark et al. (1993). 

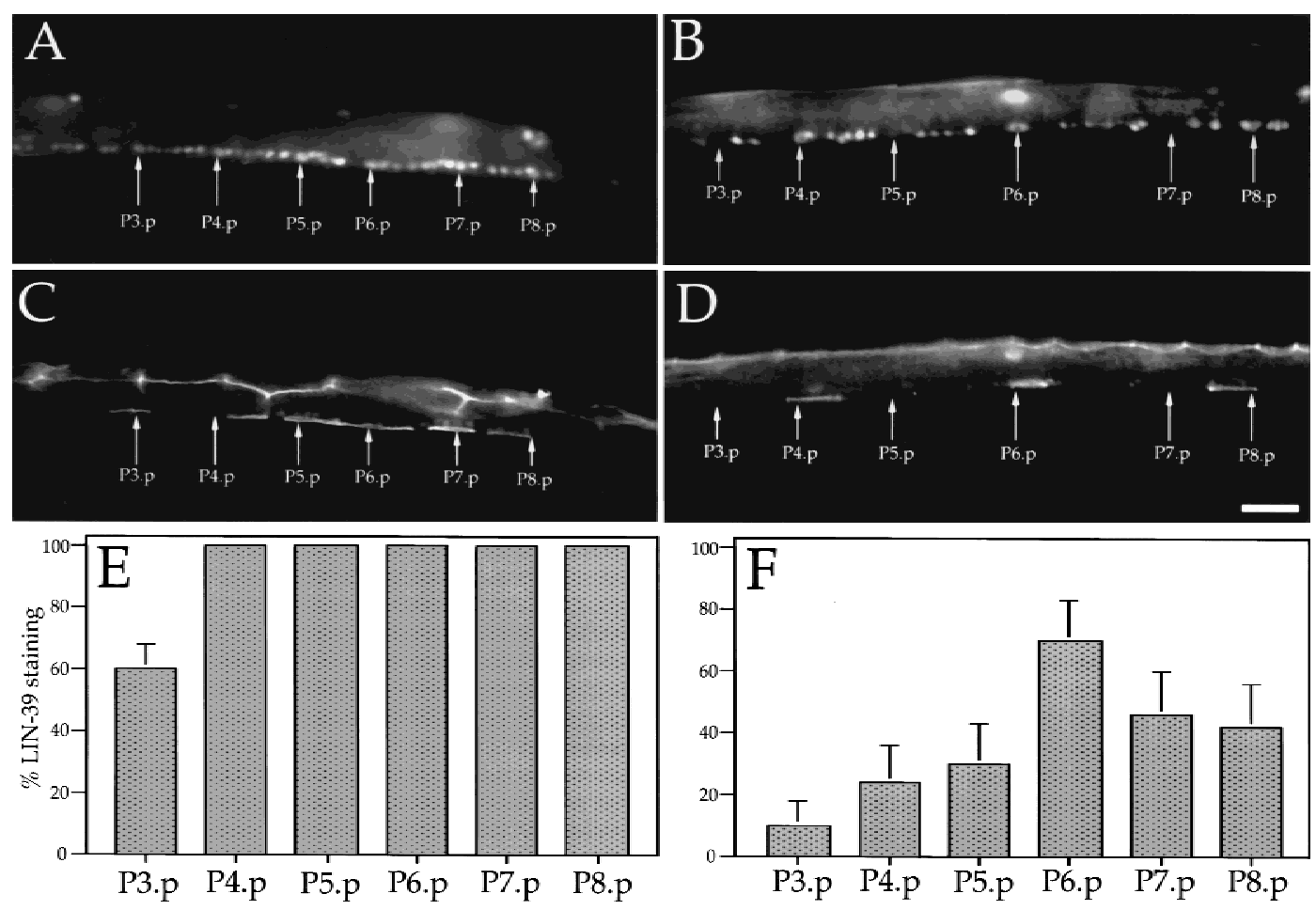

Figure 7. apr-1 regulates 1in-39 expression in P3-8.p. LIN-39 antibody staining of wild-type (A) and gaIs44[1in-31::apr-1i] L2 larvae (B). The arrows point at the positions of the Pn.p nuclei as determined by parallel staining with DAPI (not shown). (C,D) mAb MH27 staining of the animals shown in $A$ and $B$, respectively. Note that in the gaIs44[1in-31::apr-1i] animal shown in $B$ and $D$, P3.p, P5.p, and P7.p failed to express LIN-39 and adopted an F fate as indicated by the absence of adherens junctions. LIN-39 expression in the individual Pn.p cells was scored in 50 wild-type $(E)$ and 50 gaIs44[lin-31::apr-1i] L3 larvae $(F)$ and the frequencies of LIN-39-positive cells are given as percent values. Error bars, the upper 95\% confidence intervals. Scale bar in $D, 10 \mu \mathrm{m}$.

al. 1999). Inactivation of apr-1 in the Pn.p cells causes P3-8.p to adopt an F cell fate, similar to mutations in the Hox gene lin-39 (Clark et al. 1993; Wang et al. 1993). In both cases, apr-1 is necessary for the expression of the respective Hox genes (Fig. 8A,B).

A Wnt signal that is transduced by the $\beta$-catenin-related gene bar-1 induces expression of 1in-39 in P3-8.p (Eisenmann et al. 1998). Thus, apr-1 may act in the Wnt signaling pathway in P3-8.p. Inactivation of apr-1 in the
Pn.p cells by RNAi does not cause all six of the P3-8.p cells to adopt an F fate, suggesting that apr-1 may not be absolutely required for Wnt signaling. Pn.p cells that are distal to the anchor cell more frequently adopt an $\mathrm{F}$ fate and down-regulate lin-39 expression than those proximal to the anchor cell. A similar bias in the frequency of $\mathrm{F}$ fates has been observed in bar-1 mutants (Eisenmann et al. 1998). One possible explanation for this finding is that proximal Pn.p cells may be closer to the source of the

Figure 8. Models for the different functions of APR-1. (A) During morphogenesis of the embryo, APR-1 may perform at least two separate functions. First, (left) APR-1 may act together with the adherens junction proteins HMR-1 Cadherin, HMP-1 $\alpha$ Catenin, and HMP-2 $\beta$-Catenin in migratory hypodermal cells during ventral closure and elongation of the embryo. Second (right), APR-1 may act in the Wnt signaling pathway that controls the expression of the HOX protein $\mathrm{CEH}-13$ in the anterior seam and muscle cells. $(B)$ During larval development, APR-1 may be required for the trans-

A

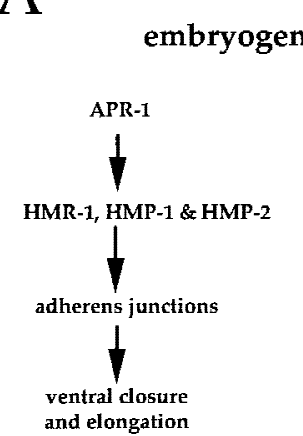

B vulval precursor cells (P3-8.p)

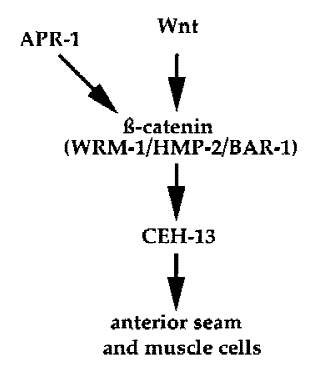

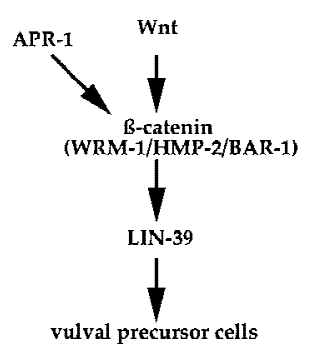

vulval precursor cells

duction of a Wnt signal that induces expression of the HOX protein LIN-39 in P3-8.p to specify the VPC fate. The three $\beta$-Catenins WRM-1 (Rocheleau et al. 1997), HMP-2 (Costa et al. 1998), and BAR-1 (Eisenmann et al. 1998) may act redundantly in the transduction of Wnt signals. 
Wnt signal in the central body region and thus require less apr-1 or bar-1 activity than distal Pn.p cells. Moreover, because loss of bar-1 function results in an incompletely penetrant vulval phenotype, one of the other two $\beta$-catenin homologs (hmp-2 or wrm-1) may be partially redundant with bar-1 in the transduction of a Wnt signal in P3-8.p. Consistent with this hypothesis, inactivation of apr-1 in animals carrying a bar-1 loss-of-function mutation appears to further decrease the activity of the Wnt signaling pathway.

Less is known about a putative Wnt signal that may control ceh-13 expression during embryogenesis. However, the ceh-13 gene contains a putative LEF-1/Tcfbinding site that plays a role in the transcriptional activation of ceh-13 in the E lineage (R. Köhler and F. Müller, pers. comm.). Because the Wnt signaling pathway controls the activity of the LEF-1/TcF family of transcription factors (Brunner et al. 1997; van de Wetering et al. 1997), ceh-13 expression may be regulated by Wnt signals. Furthermore, expression of the ceh-13 homolog labial in the Drosophila midgut is controlled by a Wnt signal (Bienz 1994). These observations together with our data suggest that apr-1 may be required to transduce a Wnt signal that induces ceh-13 expression in anterior cells of the embryo (Fig. 8A). It is not clear which of the three $C$. elegans $\beta$-catenin/armadillo homologs may participate in the transduction of this putative Wnt signal. hmp-2 mutant embryos do not exhibit defects in the alignment of seam cells (Costa et al. 1998) and they continue to express ceh-13 until the terminal stage (our observation), bar-1 mutant embryos do not exhibit an embryonic phenotype (Eisenmann et al. 1998) and no wrm-1 mutation has been described to date (Rocheleau et al. 1997). However, two or all three of the $\beta$-catenin/armadillo-related genes might act redundantly.

\section{APR-1 is necessary for $\beta$-Catenin/Armadillo function}

Vertebrate and Drosophila APCs bind to $\beta$-Catenin/Armadillo proteins and promote their proteolytic degradation (Munemitsu et al. 1995; Polakis 1997). Mutations that remove the $\beta$-Catenin-binding site of APC cause the cytoplasmic accumulation of $\beta$-Catenin, resulting in the constitutive activation of the Wnt signaling pathway. Thus, APC is thought to antagonize $\beta$-Catenin/Armadillo function.

Our data and a prior analysis of maternal apr-1 activity in early embryonic development by RNAi (Rocheleau et al. 1997) have indicated an opposite function for APR-1. In all cases that were studied, loss of apr-1 function resulted in essentially the same phenotype as loss of $\beta$-catenin function. In particular, we have found that APR-1 is necessary for HMP-2 function during morphogenesis of the embryo and BAR-1 function in the transduction of a Wnt signal in P3-8.p.

How could this apparent reversal of APR-1 activity in comparison with APC in other species be explained? One possibility is that, although APR-1 is most similar to vertebrate and Drosophila APC, apr-1 may not be a functional APC homolog. Because no second gene encod- ing a protein with significant homology to APC has been found in the C. elegans genome, $\beta$-Catenins in C. elegans may not be subject to the same kind of negative regulation by APC as in other organisms. On the other hand, the activating function of APR-1 may reflect a unique requirement of the $C$. elegans $\beta$-Catenin homologs.

Another model predicts that APC may activate as well as inhibit $\beta$-Catenin/Armadillo function. The apr-1 lossof-function mutation described in this work may disrupt both activities, and loss of the activating function may prevail over loss of the inhibitory function. In contrast, the carboxy-terminal truncations found in vertebrate and Drosophila APC (Su et al. 1992; Polakis 1995; Ahmed et al. 1998) may selectively disrupt the inhibitory function of APC, resulting in the constitutive activation of $\beta$-Catenin/Armadillo. Supporting this hypothesis, overexpression of human APC in Xenopus laevis embryos induces axis duplication, as does overexpression of $\beta$-Catenin or Xwnt-8, suggesting that human APC may also have an activating function in the Wnt signaling pathway (Vleminckx et al. 1997). Such a dual model for APC may also explain why mutations that result in the complete loss of the APC protein are usually not found in human cancer cells, as loss of the entire APC protein might inhibit rather than activate $\beta$-Catenin function and may not lead to colon cancer.

\section{Materials and methods}

\section{General methods and strains}

C. elegans strains were cultured at $20^{\circ} \mathrm{C}$ as described in Brenner (1974). Wild type refers to C. elegans variety Bristol, strain N2. Pn.p cell lineages were determined by direct observation of the cell divisions using Nomarski optics, as described previously (Sternberg and Horvitz 1986). Unless noted otherwise, the mutations used have been described (Riddle et al. 1997) and are listed below.

LGI, unc-13(e51), apr-1(zh10) (see below), lin-10(e1439), unc29(e1072), lin-11(n566); LGIII, unc-119(e2498), lin-39(n1880) (Clark et al. 1993); LGIV, him-5(e1490), swIs1[ceh-13::GFP] (Wittmann et al. 1997), gaIs44[1in-31::apr-1i] (see below), jcIs1 [jam-1::GFP] (Mohler et al. 1998); LGX, bar-1 (ga80) (Eisenmann et al. 1998); LG not determined, zhIs2[apr-1::GFP] (see below).

\section{Isolation of the apr-1(zh10) deletion}

A library consisting of $\sim 4.8 \times 10^{5}$ mutagenized $\mathrm{F}_{1}$ animals was screened for deletions in the apr-1 locus using the strategy described (Jansen et al. 1997) except for the following modifications: Wild-type animals were treated with $75 \mathrm{~mm}$ EMS, allowed to recover for $16 \mathrm{hr}$ and five $\mathrm{P}_{0}$ animals were plated on each of 960 NGM plates $(6-\mathrm{cm}$ diam.) such that each plate contained on the average 500 mutagenized $F_{1}$ animals. The cultures were grown for 7 days before harvesting one-third of the animals for DNA isolation. To identify the plate containing the apr-1(zh10) deletion, DNA extracted from the individual cultures was combined in pools of 12 cultures and $50 \mathrm{ng}$ of DNA from each pool was subjected to PCR analysis with the primers O96 (5'-CGTAAACGTAGGGACACCGAGGAG- 
GAGG-3') and O100 (5'-CAATACGACAGTTCGACGAGC-3') for the first amplification step followed by a second amplification with the nested primers O95 (5'-CGACATGACGTCGGTATAGGACGGCTTAG-3') and O101 (5'-AGAAGATGTTGAAGGACT- $\left.3^{\prime}\right)$. The remaining animals from the culture containing the $z h 10$ deletion were subjected to three rounds of selection until a single animal of the genotype apr-1(zh10)/+ had been identified. Before phenotypic analysis, the apr-1(zh10) mutation was backcrossed at least 10 times against unc29(e1072); him-5(e1490) animals.

\section{Strain construction}

Standard methods were used to construct double and triple mutants (Brenner 1974). The apr-1(zh10) deletion was cis-linked to the unc-29(e1072) mutation and followed by PCR amplification with the primers O95 and O101 (see above) or by observing the closely linked Unc phenotype. Strains heterozygous for the apr1(zh10) mutation were balanced either with lin-10(e1439) or with unc-13(e51) lin-11(n566) as indicated in the Figure legends 1-4. apr-1(zh10) unc-29(e1072)/lin-10(e1439) animals segregated $<1 \%$ viable Unc animals $(n>500)$ that were most likely recombinants between apr-1 and unc-29, because they were heterozygous for the apr-1(zh10) mutation as determined by PCR analysis. Strains that were homozygous for apr-1(zh10) contained a rescuing apr-1 transgene on the extrachromosomal array $z h E x 11$ (see below).

\section{Molecular biology}

The rescuing wild-type apr-1 construct (apr-1wt) was obtained by ligation of a 7.3-kb-long PCR product amplified from wildtype genomic DNA with the primers 5'-CGAAGCCGCAAATTCTGCGAA-3' TC and 5'-TTTCTCCCATTCCTGCCGATTTC-3' into the vector pGEM-T (Invitrogen). To construct the apr-1::GFP reporter, a $4.8-\mathrm{kb}$ SalI-BamHI fragment isolated from apr-1wt was cloned into the SalI and BamHI sites of the GFP vector pPD95.67 (gift of A. Fire, Carnegie Institution, Baltimore, MD). The plasmid $\operatorname{lox} P>a p r-1>\operatorname{lox} P$ was obtained by inserting synthetic double-stranded oligonucleotides containing the $\operatorname{lox} P$ site $5^{\prime}$-ATAACTTCGTATAATGTATGCTATACGAAGTTAT-3' (Kilby et al. 1993) into the BpuAI and SphI sites of plasmid apr-1wt. A clone carrying the two lox $P$ sites in a parallel orientation was identified by sequence analysis. For the construction of the lin-31::cre plasmid, a 1.1-kb cDNA fragment containing the entire cre recombinase ORF was isolated by PCR amplification with the primers $5^{\prime}$-TTTCTCGAGATGTCCAATTTACTGACCGTAC-3' and 5' -TTTGCGGCCGCCTAATCGCCATCTTCCAGCAGG-3' from the plasmid pCAGGS-cre (Araki et al. 1995), digested with XhoI and NotI and cloned into the SalI and NotI sites of plasmid pB253 (Tan et al. 1998). The plasmid lin-31::apr-1i was obtained by cloning a $1.3-\mathrm{kb}$ XhoI fragment of the apr-1 cDNA (nucleotides 85-1445 the coding sequence) into the SalI site of pB253 in the antisense orientation.

\section{Antibody production, immunofluorescence, and microscopy}

A $1.3-\mathrm{kb}$ apr-1 cDNA fragment was isolated from a partial cDNA clone by PCR amplification with the primers $5^{\prime}$-TTTGGATCCACGGAGGATCAAGCGCAAATG-3' and 5'-TTTGGATCCGAACAGGCAGTCTTGACTTTCC-3' and cloned into the BamHI site of the Escherichia coli expression vector pDS6 (Stueber and Bujard 1982) to produce an APR-1 fragment consisting of amino acids 551-983 with an amino-terminal $\mathrm{His}_{6}$ tag. The $\mathrm{His}_{6}:$ APR-1 fusion protein was produced in the E. coli strain M15, purified on NTA agarose according to the manufacturer's instructions (Qiagen), and used to immunize rats and rabbits. Antisera were affinity purified against the recombinant APR-1 fragment immobilized on PVDF membranes (Immobilon).

Staining of embryos and staged larvae with rat anti-APR-1 antibodies was carried out as described (Miller and Shakes 1995), except that fixation was done in ice-cold methanol/acetone (1:1) for $5 \mathrm{~min}$ followed by air-drying. Rabbit anti-LIN-39 antibodies were preadsorbed against a total extract from lin39(n1880) animals before use, and LIN-39 staining was performed as described (Maloof and Kenyon 1998). CEH-13::GFP was observed in living embryos mounted on agarose pads in M9 solution. In all staining experiments, the mAb MH27 (Francis and Waterston 1985) was included to label the adherens junctions. As secondary reagents, fluorescein-conjugated donkey anti-rat (Jackson laboratories), Alexa488-conjugated goat antirabbit (Molecular probes), and rhodamine-conjugated donkeyanti-mouse antibodies (Jackson laboratories) were used. DAPI was included during the incubations with secondary antibodies at a concentration of $0.5 \mu \mathrm{g} / \mathrm{ml}$ to label the nuclei of the cells. Fluorescent images were recorded by confocal laser scanning microsopy (Leica TC 4D or Bio-Rad MRC 600) or with a cooled CCD camera (Hammamatsu C4742-95) on a Leica DM/IR B inverted microscope. Embryos carrying the jcIs1 array were observed by four-dimensional microscopy using two-photon excitation as described (Mohler and White 1998; Mohler et al. 1998).

\section{Transgenic animals}

Transgenic animals were generated by microinjection of DNA into the distal arms of the gonad as described (Mello et al. 1991). Where indicated, extrachromosomal arrays were integrated into the genome by $\gamma$-irradiation of L4 larvae. Animals carrying integrated arrays were backcrossed at least five times before further analysis.

To rescue the lethal and vulvaless phenotypes caused by the apr-1(zh10) mutation, the plasmid apr-1wt was injected at a concentration of $100 \mathrm{ng} / \mu \mathrm{l}$ along with $100 \mathrm{ng} / \mu \mathrm{l}$ sur-5::GFP plasmid pTG96 (Yochem et al. 1998) as transformation marker into apr-1(zh10) unc-29(e1072)/lin-10(e1439) animals yielding the extrachromosomal array $z h E x 3$. Transformants were identified with a dissecting microscope under fluorescent light illumination. apr-1(zh10) unc-29(e1072); zhEx3[apr-1wt] animals developed into healthy adults that were sterile, presumably because apr-1 is required for oogenesis and the multicopy apr-1 transgene was not active in the germ line. The sterility caused by apr-1(zh10) could be rescued when a low concentration of a rescue construct was injected together with an excess of genomic DNA to allow germ-line expression of the transgene as described below for the zhEx11 array. The zhEx2 array was obtained by injecting $100 \mathrm{ng} / \mathrm{\mu l}$ plasmid apr-1wt along with 50 $\mathrm{ng} / \mathrm{\mu l}$ plasmid pRF4, which contains the semidominant marker rol-6(su1006) into $\mathrm{N}_{2}$ animals. The plasmids apr-1::GFP, lin31::cre, and lin-31::apr-1i were each injected at a concentration of $100 \mathrm{ng} / \mu \mathrm{l}$ together with $20 \mathrm{ng} / \mathrm{\mu l}$ wild-type unc-119 plasmid (Maduro and Pilgrim 1995) into unc-119(e2498) animals to yield the arrays zhIs2, zhEx12, and gaIs44, respectively. The plasmid $\operatorname{lox} P>\operatorname{apr}-1>\operatorname{lox} P$ was linearized with NotI and injected at a concentration of $5 \mathrm{ng} / \mu \mathrm{l}$ together with $200 \mathrm{ng} / \mu \mathrm{l}$ yeast genomic DNA and $5 \mathrm{ng} / \mathrm{ul}$ transformation marker pTG96 linearized with EagI into apr-1(zh10) unc-29(e1072)/lin-10(e1439) animals. The resulting array $z h E x 11$ rescued the sterility, lethality, and vulvaless phenotypes of apr-1(zh10) animals. For each construct, at least three independent lines were obtained and a representative line was kept for further analysis. 


\section{Acknowledgments}

We thank G. Battu, T. Berset, E. Brunner, R. Klemenz, K. Senn, and J. Simske for critical review of the manuscript, T. Höchli and T. Bächi for help with microscopy, T. Rühlicke for help with microinjections, and J. White and D. Wokosin for use of the 2-photon microscope. We are also grateful to C. Kenyon and colleagues for providing LIN-39 antisera, R. Waterston for the $\mathrm{mAb}$ MH27, K. Brunschwig and F. Müller for the swIs1[ceh13::GFP] strain, J. Simske and J. Hardin for the icIs1[jam$1:: G F P]$ strain and A. Fire for GFP reporter plasmids. Some strains used were provided by the C. elegans genetics center. This research was supported by grants from the kantonalzürcherische Krebsliga and the Sassella Foundation to A.H., by NIH postdoctoral fellowship GM18200-03 to W.A.M. and by the Kanton of Zürich.

The publication costs of this article were defrayed in part by payment of page charges. This article must therefore be hereby marked "advertisement" in accordance with 18 USC section 1734 solely to indicate this fact.

\section{References}

Ahmed, Y., S. Hayashi, A. Levine, and E. Wieschaus. 1998. Regulation of Armadillo by a Drosophila APC inhibits neuronal apoptosis during retinal development. Cell 93: 11711182 .

Araki, K., M. Araki, J. Miyazaki, and P. Vassalli. 1995. Sitespecific recombination of a transgene in fertilized eggs by transient expression of Cre recombinase. Proc. Natl. Acad. Sci. 92: 160-164.

Baeg, G.H., A. Matsumine, T. Kuroda, R.N. Bhattacharjee, I. Miyashiro, K. Toyoshima, and T. Akiyama. 1995. The tumour suppressor gene product APC blocks cell cycle progression from G0/G1 to S phase. EMBO J. 14: 5618-5625.

Bensimhon, M., J. Gabarro Arpa, R. Ehrlich, and C. Reiss. 1983. Physical characteristics in eucaryotic promoters. Nucleic Acids Res. 11: 4521-4540.

Bienz, M. 1994. Homeotic genes and positional signalling in the Drosophila viscera. Trends Genet. 10: 22-26.

Brenner, S. 1974. The genetics of C. elegans. Genetics 77: 7194.

Brunner, E., O. Peter, L. Schweizer, and K. Basler. 1997. pangolin encodes a Lef-1 homologue that acts downstream of Armadillo to transduce the Wingless signal in Drosophila. $\mathrm{Na}$ ture 385: 829-833.

Brunschwig, K., C. Wittmann, R. Schnabel, T.R. Burglin, H. Tobler, and F. Muller. 1999. Anterior organization of the C. elegans embryo by the labial-like Hox gene ceh-13. Development 126: 1537-1546.

Clark, S.G., A.D. Chisholm, and H.R. Horvitz. 1993. Control of cell fates in the central body region of C. elegans by the homeobox gene lin-39. Cell 74: 43-55.

Costa, M., W. Raich, C. Agbunag, B. Leung, J. Hardin, and J.R. Priess. 1998. A putative Catenin-Cadherin system mediates morphogenesis of the C. elegans embryo. I. Cell Biol. 141: 297-308.

Eisenmann, D.M., J.N. Maloof, J.S. Simske, C. Kenyon, and S.K. Kim. 1998. The $\beta$-Catenin homolog BAR-1 and LET-60 Ras coordinately regulate the Hox gene lin-39 during C. elegans vulval development. Development 125: 3667-3680.

Fire, A., D. Albertson, S.W. Harrison, and D.G. Moerman. 1991. Production of antisense RNA leads to effective and specific inhibition of gene expression in C. elegans muscle. Development 113: 503-514.

Francis, G.R. and R.H. Waterston. 1985. Muscle organization in
C. elegans: Localization of proteins implicated in thin filament attachment and I-band organization. I. Cell Biol. 101: 1532-1549.

Jansen, G., E. Hazendonk, K.L. Thijssen, and R.H. Plasterk. 1997. Reverse genetics by chemical mutagenesis in C. elegans. Nat. Genet. 17: 119-121.

Jiang, L.I. and P.W. Sternberg. 1998. Interactions of EGF, Wnt and HOM-C genes specify the P12 neuroectoblast fate in $C$. elegans. Development 125: 2337-2347.

Kilby, N.J., M.R. Snaith, and J.A. Murray. 1993. Site-specific recombinases: Tools for genome engineering. Trends Genet. 9: 413-421.

Kinzler, K.W. and B. Vogelstein. 1996. Lessons from hereditary colorectal cancer. Cell 87: 159-170.

Korinek, V., N. Barker, P.J. Morin, D. van Wichen, R. de Weger, K.W. Kinzler, B. Vogelstein, and H. Clevers. 1997. Constitutive transcriptional activation by a $\beta$-Catenin-Tcf complex in APC-/- colon carcinoma. Science 275: 1784-1787.

Lawrence, P.A. and G. Morata. 1994. Homeobox genes: Their function in Drosophila segmentation and pattern formation. Cell 78: 181-189.

Maduro, M. and D. Pilgrim. 1995. Identification and cloning of unc-119, a gene expressed in the C. elegans nervous system. Genetics 141: 977-988.

Maloof, J.N. and C. Kenyon. 1998. The Hox gene lin-39 is required during C. elegans vulval induction to select the outcome of Ras signaling. Development 125: 181-190.

Maloof, J.N., J. Whangbo, J.M. Harris, G.D. Jongeward, and C. Kenyon. 1999. A Wnt signaling pathway controls hox gene expression and neuroblast migration in C. elegans. Development 126: 37-49.

McCartney, B.M., H.A. Dierick, C. Kirkpatrick, M.M. Moline, A. Baas, M. Peifer, and A. Bejsovec. 1999. Drosophila APC2 is a cytoskeletally-associated protein that regulates wingless signaling in the embryonic epidermis. I. Cell Biol. 146: $1303-1318$.

McGinnis, W. and R. Krumlauf. 1992. Homeobox genes and axial patterning. Cell 68: 283-302.

Mello, C.C., J.M. Kramer, D. Stinchcomb, and V. Ambros. 1991. Efficient gene transfer in C. elegans: Extrachromosomal maintenance and integration of transforming sequences. EMBO T. 10: 3959-3970.

Miller, D.M. and D.C. Shakes. 1995. Immunofluorescence microscopy. Methods Cell Biol. 48: 365-394.

Mohler, W.A. and J.G. White. 1998. Multiphoton laser scanning microscopy for four-dimensional analysis of C. elegans embryonic development. Optics Express 3: 325-331.

Mohler, W.A., J.S. Simske, E.M. Williams Masson, J.D. Hardin, and J.G. White. 1998. Dynamics and ultrastructure of developmental cell fusions in the C. elegans hypodermis. Curr. Biol. 8: 1087-1090.

Morin, P.J., B. Vogelstein, and K.W. Kinzler. 1996. Apoptosis and APC in colorectal tumorigenesis. Proc. Nat1. Acad. Sci. 93: 7950-7954.

Morin, P.J., A.B. Sparks, V. Korinek, N. Barker, H. Clevers, B. Vogelstein, and K.W. Kinzler. 1997. Activation of $\beta$-CateninTcf signaling in colon cancer by mutations in $\beta$-Catenin or APC. Science 275: 1787-1790.

Munemitsu, S., I. Albert, B. Souza, B. Rubinfeld, and P. Polakis. 1995. Regulation of intracellular $\beta$-Catenin levels by the adenomatous polyposis coli (APC) tumor-suppressor protein. Proc. Natl. Acad. Sci. 92: 3046-3050.

Nathke, I.S., C.L. Adams, P. Polakis, J.H. Sellin, and W.J. Nelson. 1996. The adenomatous polyposis coli tumor suppressor protein localizes to plasma membrane sites involved in active cell migration. J. Cell Biol. 134: 165-179. 
Peifer, M. 1999. Signal transduction: Neither straight nor narrow. Nature 400: 213-215.

Podbilewicz, B. and J.G. White. 1994. Cell fusions in the developing epithelia of C. elegans. Dev. Biol. 161: 406-424.

Polakis, P. 1995. Mutations in the APC gene and their implications for protein structure and function. Curr. Opin. Genet. Dev. 5: 66-71.

. 1997. The adenomatous polyposis coli (APC) tumor suppressor. Biochim. Biophys. Acta 1332: 127-147.

Pollack, A.L., A.I.M. Barth, Y. Altschuler, W.J. Nelson, and K.E. Mostov. 1997. Dynamics of $\beta$-Catenin interactions with APC protein regulate epithelial tubulogenesis. J. Cell Biol. 137: $1651-1662$

Priess, J.R. and D.I. Hirsh. 1986. C. elegans morphogenesis: The role of the cytoskeleton in elongation of the embryo. Dev. Biol. 117: 156-173.

Raich, W.B., C. Agbunag, and J. Hardin. 1999. Rapid epithelialsheet sealing in the Caenorhabditis elegans embryo requires cadherin-dependent filopodial priming. Curr. Biol. 9: 11391146.

Riddle, D.L., T. Blumenthal, B.J. Meyer, and J.R. Priess. 1997. In C. elegans II (ed. D.L. Riddle, T. Blumenthal, B.J. Meyer, and J.R. Priess), pp. 902-1047. Cold Spring Harbor Laboratory Press, Cold Spring Harbor, NY

Rocheleau, C.E., W.D. Downs, R. Lin, C. Wittmann, Y. Bei, Y.H. Cha, M. Ali, J.R. Priess, and C.C. Mello. 1997. Wnt signaling and an APC-related gene specify endoderm in early C. elegans embryos. Cell 90: 707-716.

Rubinfeld, B., B. Souza, I. Albert, O. Muller, S.H. Chamberlain, F.R. Masiarz, S. Munemitsu, and P. Polakis. 1993. Association of the APC gene product with $\beta$-Catenin. Science 262: $1731-1734$

Salser, S.J. and C. Kenyon. 1994. Patterning C. elegans: Homeotic cluster genes, cell fates and cell migrations. Trends Genet. 10: 159-164.

Sternberg, P.W. and H.R. Horvitz. 1986. Pattern formation during vulval development in C. elegans. Cell 44: 761-772.

Stueber, D. and H. Bujard. 1982. Transcription from efficient promoters can interfere with plasmid replication and diminish expression of plasmid specified genes. EMBO J. 1: 1399_ 1404.

Su, L.K., K.W. Kinzler, B. Vogelstein, A.C. Preisinger, A.R. Moser, C. Luongo, K.A. Gould, and W.F. Dove. 1992. Multiple intestinal neoplasia caused by a mutation in the murine homolog of the APC gene. Science 256: 668-670.

Sulston, J.E. and H.R. Horvitz. 1977. Post-embryonic cell lineages of the nematode, C. elegans. Dev. Biol. 56: 110-156.

Sulston, J.E., E. Schierenberg, J.G. White, and J.N. Thomson. 1983. The embryonic cell lineage of the nematode C. elegans. Dev. Biol. 100: 64-119.

Tan, P.B., M.R. Lackner, and S.K. Kim. 1998. MAP kinase signaling specificity mediated by the LIN-1 Ets/LIN-31 WH transcription factor complex during C. elegans vulval induction. Cell 93: 569-580.

van de Wetering, M., R. Cavallo, D. Dooijes, M. van Beest, J. van Es, J. Loureiro, A. Ypma, D. Hursh, T. Jones, A. Bejsovec et al. 1997. Armadillo coactivates transcription driven by the product of the Drosophila segment polarity gene dTCF. Cell 88: 789-799.

Vleminckx, K., E. Wong, K. Guger, B. Rubinfeld, P. Polakis, and B.M. Gumbiner. 1997. Adenomatous polyposis coli tumor suppressor protein has signaling activity in Xenopus laevis embryos resulting in the induction of an ectopic dorsoanterior axis. J. Cell Biol. 136: 411-420.

Wang, B.B., I.M. Muller, J. Austin, N.T. Robinson, A. Chisholm, and C. Kenyon. 1993. A homeotic gene cluster patterns the anteroposterior body axis of C. elegans. Cell 74: 29-42.

Williams Masson, E.M., A.N. Malik, and J. Hardin. 1997. An actin-mediated two-step mechanism is required for ventral enclosure of the C. elegans hypodermis. Development 124: 2889-2901.

Williams Masson, E.M., P.J. Heid, C.A. Lavin, and J. Hardin. 1998. The cellular mechanism of epithelial rearrangement during morphogenesis of the C. elegans dorsal hypodermis. Dev. Biol. 204: 263-276.

Wittmann, C., O. Bossinger, B. Goldstein, M. Fleischmann, R. Kohler, K. Brunschwig, H. Tobler, and F. Muller. 1997. The expression of the C. elegans labial-like Hox gene ceh-13 during early embryogenesis relies on cell fate and on anteroposterior cell polarity. Development 124: 4193-4200.

Wodarz, A. and R. Nusse. 1998. Mechanisms of Wnt signaling in development. Annu. Rev. Cell Dev. Biol. 14: 59-88.

Wong, M.H., M.L. Hermiston, A.J. Syder, and J.I. Gordon. 1996. Forced expression of the tumor suppressor adenomatosis polyposis coli protein induces disordered cell migration in the intestinal epithelium. Proc. Natl. Acad. Sci. 93: 95889593.

Yochem, J., T. Gu, and M. Han. 1998. A new marker for mosaic analysis in C. elegans indicates a fusion between hyp6 and hyp7, two major components of the hypodermis. Genetics 149: $1323-1334$.

Yu, X., L. Waltzer, and M. Bienz. 1999. A new Drosophila APC homologue associated with adhesive zones of epithelial cells. Nat. Cell Biol. 1: 144-151. 


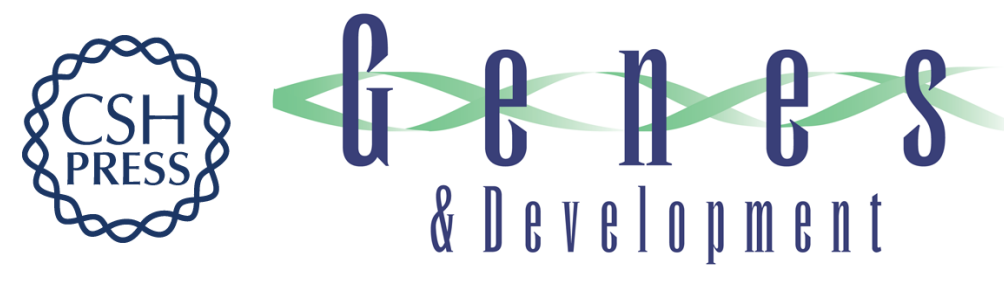

\section{The Caenorhabditis elegans APC-related gene apr-1 is required for epithelial cell migration and Hox gene expression}

Erika Fröhli Hoier, William A. Mohler, Stuart K. Kim, et al.

Genes Dev. 2000, 14:

Access the most recent version at doi:10.1101/gad.14.7.874

$\begin{array}{ll}\text { References } & \begin{array}{l}\text { This article cites } 57 \text { articles, } 25 \text { of which can be accessed free at: } \\ \text { http://genesdev.cshlp.org/content/14/7/874.full.html\#ref-list-1 }\end{array}\end{array}$

License

Email Alerting Receive free email alerts when new articles cite this article - sign up in the box at the top Service right corner of the article or click here.

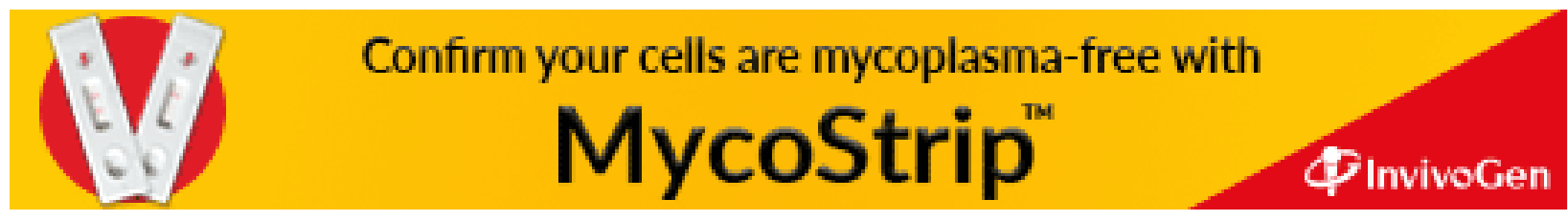

